(C) Copyright 2019: Editum. Servicio de Publicaciones de la Universidad de Murcia. Murcia (Spain) ISSN print edition: 0212-9728. ISSN on line edition (http://revistas.um.es/analesps): 1695-2294. On line edition License Creative Commons 4.0: BY-NC-ND

\title{
Prevention of Depressive Symptoms and Promotion of Well-being in Adolescents: A Randomized Controlled Trial of the Smile Program
}

\author{
Óscar Sánchez-Hernández ${ }^{1, *}$, Francisco X. Méndez ${ }^{1}$, Manuel Ato ${ }^{1}$, and Judy Garber ${ }^{2}$ \\ 1 University of Murcia (Spain). \\ 2 Vanderbilt University, Nashville (EE. UU.)
}

\begin{abstract}
Título: Prevención de Síntomas Depresivos y Promoción del Bienestar: Un ensayo controlado aleatorizado del Programa Sonrisa.

Resumen: Este estudio consistió en describir el desarrollo y la evaluación del Programa Sonrisa, cuyo principal objetivo fue la prevención de la depresión y la promoción del bienestar en adolescentes. El programa se basa en intervenciones que han demostrado ser eficaces (enfoque cognitivo-conductual). Los participantes fueron 89 adolescentes (edad media $=$ 13,88 años, $D T=0,95$ ) reclutados de una muestra de 1212 estudiantes de 7 escuelas. Los resultados de los autoinformes de los adolescentes mostraron una reducción significativa en los síntomas depresivos en el grupo de intervención $(n=51)$ en comparación con los adolescentes del grupo control ( $n$ $=38$ ). Respecto a los cuestionarios de los padres $(n=56)$, se halló que los adolescentes en el grupo de intervención tuvieron una autoestima significativamente mejor en el postest en comparación con los del grupo control. Cuatro meses después del programa, los adolescentes del grupo de intervención tenían mayor bienestar psicológico que los del grupo de control y, en el seguimiento de 8 meses, los adolescentes de la condición de intervención informaron de mejor autoconcepto familiar.
\end{abstract}

Palabras clave: prevención; depresión; adolescentes; bienestar.

\section{Introduction}

According to the World Health Organization, in the year 2000 , depression was the fourth leading cause of disability, and by 2020,depression will be second only to ischemic heart disease (see http://www.who.int/topics/depression/en/). Moreover, a study conducted in six European countries revealed that Spain had the most people with anxiety and depression (King et al., 2008). The point prevalence of major depression is $0.5 \%$ for children under age $6,2.5 \%$ for children ages 6 to 12 , and $6.5 \%$ for teens 13 years and above (Méndez, Olivares, \& Ros, 2001). In a community sample of 1,705 youth, ages 10 to $18,9.2 \%$ scored above the clinical cutoff on the Children's Depression Inventory (Figueras et al., 2010). In addition, the rates of depression have been found to increase during the adolescent years (Hankin, Abramson, Moffitt, Silva, \& McGee, 1998; Meltzer, Gatward, Goodman, \& Ford, 2000). Depression also causes considerable expense to families and society. The total cost in Europe is approximately 118 billion euros, 61\% of which is due to the indirect costs of sick leave and decreased productivity. Therefore, given its prevalence, serious risk for suicide (Bustamante \& Florenzano, 2013), and impact on family finances, the prevention of depression in youth is of great importance not only to the developing child and family,

* Correspondence address [Dirección para correspondencia]: Óscar Sánchez Hernández. Facultad de Psicología. Campus Universitario de Espinardo, 30100, Murcia (Spain). España. E-mail: oscarsh@um.es (Article received: 19-09-2018; revised: 27-11-2018; accepted: 11-12-2018)
Abstract: This study addressed the development and evaluation of the Smile Program whose main objective was the prevention of depression and the promotion of well-being in adolescents. The program is based on interventions that have been shown to be efficacious (a cognitive-behavioral approach). Participants were 89 adolescents (mean age $=13.88$ years; SD $=0.95$ recruited from a sample of 1212 students from seven schools. Results showed a significant reduction in self-reported depressive symptoms in the intervention group $(n=51)$ as compared to youth in the control group $(n=38)$. Based on parents' report $(n=56)$, youth in the intervention group had significantly better self-esteem at post-test as compared to youth in the control group. At four months post intervention, youth in the intervention group had higher psychological well-being than those in the control group; at the 8-month follow-up, youth in the intervention condition reported better family self-concept.

Keywords: prevention; depression; adolescents; well-being. but also to the broader health system and society (Ferreira et al., 2012). In the past two decades, there has been increasing interest in testing the effectiveness of interventions to prevent depression in youth (e.g., Merry et al., 2011), although there has been an absence of such research in Spanish samples (Sánchez-Hernández, Méndez, \& Garber, 2014). Thus, there is a real need for more methodologically sound studies of preventive interventions that benefit personal, family, and social well-being in Spanish youth. Meta-analytic reviews of studies testing the efficacy of depression prevention programs in children and adolescents have concluded that there is sufficient evidence that some programs can prevent the onset of depressive disorders, particularly those with targeted as compared to universal samples (Horowitz \& Garber, 2006; Merry et al., 2011; Sánchez-Hernández et al., 2014; Stice et al., 2009). Huppert (2009) suggested that even a small change in the mean number of depressive symptoms can improve an individual's well-being and reduce future risk of the disorder. For example, one of the main objectives of the Penn Resiliency Program for youth (Gillham, Brunwasser, \& Freres, 2008) has been the promotion of optimism as a protective factor for depression. In addition, studies have shown that interventions to prevent depression may save money over time (Mihalopoulos et al., 2011). Thus, efforts to develop more efficient and cost-effective interventions for preventing depression are an important public health goal.

The current article presents the development and evaluation of the Smile Program (Sánchez-Hernández \& Méndez, 2009), whose main goals were to prevent depressive symp- 
toms and promote psychological well-being in young adolescents. The Smile Program combined information from basic research on risk and protective factors for depression with various prevention programs that have been found to be effective in children and adolescents (Garber, 2006; SánchezHernández, Méndez, \& Garber, 2014; Southwick, Vythilingam, \& Charney, 2005). The Smile Program also integrated psychological techniques from cognitive-behavioral techniques (e.g., cognitive restructuring, mood monitoring, optimism, emotional education). The purpose of including optimism was to complement the emphasis on psychopathology by focusing on strengths and skills that protect against psychological distress (i.e., prevention) and foster well-being (i.e., health promotion). Seligman and Csikszentmihalyi (2000) suggested that the most progress in prevention comes from targeting the systematic construction of competence. For example, one of the main objectives of the Penn Resiliency Program for youth (PRP; Gillham, Brunwasser, \& Freres, 2008) has been the promotion of optimism as a protective factor for depression.

In addition, a new module was created that aimed to promote motivation for personal growth and an adaptation of behavioral activation. Methodological strengths of the current study included randomization of participants to either an experimental intervention or a control condition, evaluation of positive outcomes as well as depressive symptoms, conducting assessments at multiple time points including 8 and 12 months (Shore, Toumbourou, Lewis and Kremer, 2017) post-randomization, and the use of new and innovative techniques in the intervention.

In summary, the main objective of the current study was to evaluate the effectiveness of the Smile Program by measuring changes over time in multiple dependent variables across several time points

\section{Method}

\section{Participants}

Participants were 89 students in grades $7(50.6 \%)$ and 8 (49.4\%); the mean age was 13.88 years $(S D=0.95)$. The sample $(51.7 \%$ female) was recruited from seven schools $(80.9 \%$ public and $19.1 \%$ concerted/private) and using a convenience sample. Parents $(74.5 \%$ mothers; mean age $=$ 43.31, $S D=5.99)$ reported about their children's depressive symptoms (response rate: $n=56,62.9 \%$ ). The socioeconomic status (SES) of the families was middle class, 39.1 points (range 8-66), according to the two primary factors of the new index of Hollingshead (2011): 5.0 points in occupation (range $1-9)$ and 4.4 points in education (range $1-7$ ).

\section{Instruments}

Primary Outcome Measures

The Children's Depression Inventory (CDI; Kovacs, 1992)Spanish adaptation (Del Barrio \& Carrasco, 2004) - was used to assess depressive symptoms in youth. The CDI is a widely used self-report measure that consists of 27 items with three response options. The CDI can be grouped into two subscales: dysphoria (16 items), and negative self-esteem (11 items). In a community sample of 1,705 participants, ages 10to 18-years-old, internal consistency Cronbach's alpha was found to be 0.82 on the full CDI (Figueras et al., 2010).

To obtain a multi-informant assessment of adolescents' depressive symptoms, parents completed the parent version of the Children's Depression Inventory - Short form (CDI-S; Kovacs, 1992; Spanish adaptation: Del Barrio et al., 2002) about their child. The CDI-S consists of 10 items. The CDI$\mathrm{S}$ also can be grouped into two subscales: dysphoria, and negative self-esteem. Cronbach's alpha of the Spanish adaptation was 0.71 .

\section{Secondary Outcome Measures}

Self-Concept Scale Form 5 (AF-5; Garcia \& Musitu, 2001) was developed in Spain and is not a translation and/or adaptation of an existing measure in English (Tomas \& Oliver, 2004). The AF-5 assesses five dimensions of self-concept (academic/work, social, emotional, family and physical). The measure consists of 30 items evaluated on a scale with 99 response options from 1 to 99 . In a sample of 6,483 participants, ages 10 to 62 years, Garcia and Musitu (2001) found a Cronbach's alpha on the total score of 0.81 .

Warwick-Edinburgh Mental Well-being Scale (WEMWBS; Tennant et al., 2007) measures positive mental health (Cooke et al., 2011). The WEMWBS has 14 positively worded items with a 5-point Likert scale for each item (from $1=$ 'none of the time' to $5=$ 'all of the time'). WEMWBS covers most aspects of mental well-being (Tennat et al., 2007) including both hedonic (positive affect: optimism, cheerfulness, and relaxation) and eudaimonic (autonomy, self-acceptance, environmental mastery, positive relations with others, personal growth, and purpose in life) perspectives. Tennant et al. (2007) reported a Cronbach's alpha of 0.89 (student sample) and 0.91 (population sample). The distribution of the WEMWBS was near normal and the scale showed no ceiling effect in the study sample.

\section{Potential Moderators}

The Sociodemographic Questionnaire (SDQ) was completed by parents. Variables used to determine the social class of the family were income, and fathers' and mothers' education and occupation.

\section{Procedures}

We contacted 12 schools (public and private) located mostly in the center of the city of Murcia (Spain). Both private and public schools were included. Seven centers agreed to implement the program. We targeted an indicated sample of youth screened for scores above 10 on the Children's De- 
pression Inventory (CDI) using a cutoff score similar to that used in other depression prevention research (Gillham et al., 2006). We sent invitation letters to adolescents in the 1 st and 2 nd year of ESO. All youth for whom we obtained parental permission were screened. Parents were informed that the study was about emotional difficulties of adolescents in the Region of Murcia (Spain).

For the screening, passive consent was used (Chartier et al., 2008), which was almost complete (99\%). Of the 1212 adolescents assessed during school hours, particularly in tutoring hours, 593 adolescents scored above 10 on the CDI $(48.73 \%)$. We then informed the teens about the opportunity to participate in a program to promote the psychological resources of adolescents and personal growth for a fuller life. We provided a letter to teens that described the program and requested parental consent.

Parents were invited to attend an informational meeting in person, or when necessary, were given information by phone. In the meetings, we explained that the objective of the program was to enhance interpersonal and intrapersonal intelligence, as described by Howard Gardner (2005). We presented the program as being part of their children's education. We invited parents to provide an assessment of their child, and 104 parents agreed to do so.

Youth participation rate was $8.8 \%(n=52)$, which is lower than other school-based depression prevention studies, which averaged around 15\% (Gillham et al., 1995; Gillham et al., 2007). Given the low participation rate, we decided to offer the program to all adolescents 1 st and 2 nd of ESO of schools recruited during the first phase, and thereby move from an indicated to a more universal sample, similar to what was done by Gillham et al. (2007). Our final number of participants was 89 students $(7.3 \%)$. Some reasons for the low participation rate are that other activities made it difficult to get program assistance outside school hours, parents had difficulty picking up their children to take them to evening schools, and a general lack of awareness about the importance of promoting psychological well-being.

During the first session, we explained the objectives of the group and highlighted the positive aspects of participating. We noted that we would have a May-June delivery of diplomas, awards, and a party for each group. Pretest assessments were conducted within the school hours dedicated to teaching the Smile Program (in the first two sessions). Intervention group members were told that those who attended a minimum of 11 sessions, including the four assessments and the ten sessions of the program, would be eligible for a prize at the end.

\section{Study design}

A mixed factorial design $(2 \times 4)$ was used with a between subjects factor (condition: Smile Program intervention versus no intervention control) and a within subjects factor (time point: pre-intervention, post-intervention, 8 and 12 months follow-up).

Adolescents whose parents signed the consent form were randomly assigned to either the experimental intervention $(n$ $=51$ ) or control condition $(n=38)$. Random assignment was generated by application software GAUSS, a vector of random numbers that were uniform in the range of values from 0 to 1 model, so that values above 0.5 would be the control group and values from 0 to 0.499 would be the experimental group. If the sample had been larger, it is likely that randomization would have balanced the groups with a more equal number of participants. A sample of 56 parents (39 in the experimental group and 17 in the control group) participated. Table 1 presents the assessment schedule.

Table 1. Participant recruitment at each phase.

\begin{tabular}{|c|c|c|c|c|c|c|}
\hline & \multicolumn{2}{|c|}{$\begin{array}{c}\text { Adolecents } \\
N\end{array}$} & \multicolumn{2}{|c|}{$\begin{array}{c}\text { Parents } \\
N\end{array}$} & & \\
\hline Letters mailed & \multicolumn{2}{|c|}{1,230} & \multicolumn{2}{|c|}{1,230} & & \\
\hline Phase 1 . Screening & \multicolumn{2}{|c|}{1,212} & \multicolumn{2}{|c|}{$1212-104^{a}$} & & \\
\hline Phase 2. Program assignment & \multicolumn{2}{|c|}{89} & \multicolumn{2}{|c|}{56} & & \\
\hline Total Participation rate $(\%)$ & \multicolumn{2}{|c|}{$7.3 \%$} & \multicolumn{2}{|c|}{$4.6 \%$} & & \\
\hline Assigned to Smile Program & \multicolumn{2}{|c|}{51} & \multicolumn{2}{|c|}{39} & & \\
\hline Assigned to Control Condition & \multicolumn{2}{|c|}{38} & \multicolumn{2}{|c|}{17} & & \\
\hline \multirow[t]{2}{*}{ Total participants } & \multirow{2}{*}{\multicolumn{2}{|c|}{$\begin{array}{c}89 \\
\text { Smile Program }\end{array}$}} & \multirow{2}{*}{\multicolumn{2}{|c|}{$\begin{array}{c}56 \\
\text { Control }\end{array}$}} & & \\
\hline & & & & & \multicolumn{2}{|c|}{ Total } \\
\hline Assessments Completed (N)b & Adol & Parents & Adol & Parents & Adol & Parents \\
\hline Total participants & 51 & 39 & 38 & 17 & 89 & 56 \\
\hline Completed Pre-intervention & 49 & 39 & 37 & 17 & 86 & 56 \\
\hline Completed Post-intervention & 47 & 36 & 30 & 13 & 77 & 49 \\
\hline Completed 4-month follow-up & 33 & & 27 & & 60 & \\
\hline Completed 8-month follow-up & 46 & 20 & 30 & 3 & 76 & \\
\hline Completed 12-month follow-up & 41 & & 28 & & 69 & \\
\hline
\end{tabular}


Table 2. Overview of the assessments.

\begin{tabular}{|c|c|}
\hline Asses & ares \\
\hline Screening & $\begin{array}{l}\text { Adolescents: Children's Depression Inventory } \\
\text { (CDI) } \\
\text { Parents: Children`s Depression Inventory - Short } \\
\text { form (CDI-S); Demographic Questionnaire } \\
\text { (DEQ) }\end{array}$ \\
\hline Pre-in & Adolescents: Self-Concept Scale Form 5 (AF-5) \\
\hline ion & $\begin{array}{l}\text { Adolescents: Children's Depression Inventory } \\
\text { (CDI); Self-Concept Scale Form } 5 \text { (AF-5) } \\
\text { Parents: Children`s Depression Inventory - Short } \\
\text { form (CDI-S); Demographic Questionnaire(DQ) }\end{array}$ \\
\hline \multicolumn{2}{|l|}{ Follow-ups at: } \\
\hline 4 months & $\begin{array}{l}\text { Adolescents: Warwick-Edinburgh Mental Well } \\
\text { being Scale (WEMWBS) }\end{array}$ \\
\hline $8 \mathrm{mo}$ & $\begin{array}{l}\text { Adolescents: Children's Depression Inventory } \\
\text { (CDI); Self-Concept Scale Form } 5 \text { (AF-5); War- } \\
\text { wick-Edinburgh Mental Well-being Scale } \\
\text { (WEMWBS) } \\
\text { Parents: Children`s Depression Inventory - Short } \\
\text { form (CDI-S); Demographic Questionnaire(DQ) }\end{array}$ \\
\hline $12 \mathrm{mc}$ & $\begin{array}{l}\text { Adolescents: Children's Depression Inventory } \\
\text { (CDI); Self-Concept Scale Form } 5 \text { (AF-5); War- } \\
\text { wick-Edinburgh Mental Well-being Scale } \\
\text { (WEMWBS) }\end{array}$ \\
\hline
\end{tabular}

\section{Intervention}

The Smile Program integrates personal development, and the promotion of psychological well-being with a clinical psychology approach aimed at relieving discomfort and preventing depression (Sánchez-Hernández \& Méndez, 2009; Sanchez-Hernandez et al., 2014). The program was implemented in groups of ten participants in eleven weekly, twohour sessions. The two group leaders used a manual and the teens were provided with activity books. Each meeting began and ended with a review of the current session and a presentation of the proposed homework, respectively, although in the first session an overview of the program was provided and in the last session there was a party and distribution of diplomas.

Program modules were as follows:

1. Motivation and emotional education: decisional balance (pros and cons) of positive change; definitions, types and usefulness of emotions; connections between situations and emotions; and deactivation techniques (relaxation, breathing and visualization).

2. Behavioral Activation: pleasant activities; sensory training (savoring); rewarding activities based on personal strengths; training in alternative active behavioral coping versus avoidance and rumination.

3. Problem Solving: attitude towards problems; problem solving procedures; games; creativity.

4. Promoting optimism: conceptualization of optimism and pessimism; attributional training.

5. Social skills: identification of passive, assertive, and aggressive styles; training for expressing disagreement and/or dislike; reject/accept requests; defend personal rights; negotiating with parents.

6. Planning goals: setting clear, specific, and realistic personal goals; reflecting on areas of development or improvement.

The group leaders were Masters level clinical psychologists who received a 25 -hour training program by the authors. To verify adherence to the program, sessions were video recorded and rated by experts in the Smile Program. The degree of agreement between judges was good (i.e., intraclass correlation coefficient $=.93$ ). The average intervention integrity was assessed for each workshop; scores ranged from $70 \%$ to $100 \%$ (mean $=94 \%, S D=1.0)$, which is consistent with other depression prevention studies in youth (Gillham et al., 2007; Roberts et al., 2003) and indicates a high level of adherence to the program.

\section{Statistical analysis}

We conducted analyses of covariance using the baseline score from the pre-intervention evaluation as the covariate, which is consistent with the statistical analyses used in other studies of the prevention of depression (e.g., Horowitz et al., 2007; Seligman et al., 2007). We also calculated effect sizes, as recommended by Frías, Pascual, and García (2000). For analysis of results regarding the effect of the program, the index $d$ is more appropriate to compare the change that occurs from pre- to post-test (as well as follow-up evaluations at eight and twelve months) in youth in one condition versus the other (Morris, 2000; Morris \& DeShon, 2002). Effect sizes were interpreted based on Cohen (1988). For scores equal or higher than 0.20 , index $d$ was considered low; scores equal or higher than 0.50 were considered medium, and scores equal or higher than 0.80 were considered high.

\section{Results}

\section{Baseline}

Youths randomized to the intervention versus control condition did not differ significantly on any demographic variables except for fathers' education $\left(\chi^{2}{ }_{6}=12.90 ; p=\right.$ $0.045)$; fathers of adolescents in the experimental group were less educated than were fathers in the control group (effect size, $\phi=0.51)$.

\section{Primary Outcome: Depressive Symptoms}

Analysis of covariance indicated that at the postintervention evaluation, youth in the intervention condition had significantly lower CDI total scores than youth in the control condition, controlling for baseline CDI scores (see Table 3 and Figure 1). The magnitude of the effect of these differences was low to medium. At the 8- or 12-month fol- 
low-up evaluations, the groups were no longer significantly differenton depressive symptoms.

On the Parent version of the Children's Depression Inventory Short form (PCDI-S), analyses of post-intervention scores, controlling for pre-intervention scores yielded a nonsignificant trend for youth in the intervention group to have lower PCDI-S total scores as compared to youth in the control group (see Table 3). The magnitude of the effect size of the differences was low to medium. A statistically significant group difference was found, however, on the PCDI-S negative self-esteem subscale, $F(1,53)=4.7, p=.033, n=55, d=$ .51 , indicating that parents reported that youth in the intervention group had significantly lower negative self-esteem at post-test than did youth in the control condition.

Table 3. Descriptives (means and standard deviations) and ANCOVAS for children's depressive symptoms on the Children's Depression Inventory (CDI) at baseline (pre), post-intervention, and the 8- and 12-month follow-up evaluations.

\begin{tabular}{|c|c|c|c|c|c|c|c|c|c|}
\hline \multirow[t]{2}{*}{ Variable } & \multirow{2}{*}{$\begin{array}{c}\text { Control } \\
\text { Mean }\end{array}$} & \multicolumn{2}{|c|}{ Group } & \multirow{2}{*}{$\begin{array}{l}\text { Smile } \\
\text { Mean }\end{array}$} & \multicolumn{2}{|c|}{ Program } & \multirow[t]{2}{*}{$F(\mathrm{df})$} & \multirow[t]{2}{*}{$p$} & \multirow[t]{2}{*}{ Effect size } \\
\hline & & $n$ & $S D$ & & $n$ & $S D$ & & & \\
\hline \multicolumn{10}{|l|}{$\overline{\mathrm{CDI}}$} \\
\hline Pre-intervention & 13.1 & 37 & .2 & 14.1 & 49 & .8 & -- & & \\
\hline Post-intervention & 12.9 & 37 & .1 & 11.1 & 49 & .0 & $4.0(1.84)$ & .048 & .39 \\
\hline 8-month follow-up & 11.6 & 35 & .1 & 11.0 & 49 & .9 & $1.3(1.82)$ & .25 & .15 \\
\hline 12-month follow-up & 11.4 & 33 & .6 & 12.1 & 49 & .9 & $0.0(1.80)$ & .95 & -.04 \\
\hline \multicolumn{10}{|l|}{ PCDI-S } \\
\hline Pre-intervention & 4.0 & 37 & 2.0 & 4.5 & 49 & .7 & -- & & \\
\hline Post-intervention & 4.0 & 37 & .0 & 3.6 & 49 & .5 & $3.4(1.54)$ & .07 & .34 \\
\hline
\end{tabular}

Notes: Results of the total scores of the measures are presented. All ANCOVAs included the pre-intervention scores as a covariate in the analyses $S D=$ standard deviation; $d f=$ degrees of freedom; CDI = Children’s Depression Inventory; PCDI-S = Parent version of the Children`s Depression Inventory - Short form

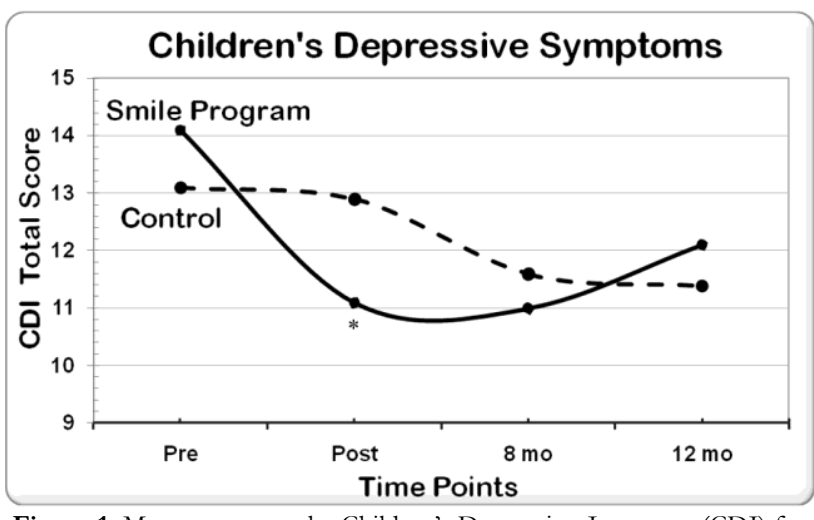

Figure 1. Mean scores on the Children's Depression Inventory (CDI) for the Smile Program versus Contols at pre- and post-intervention and at 8- and 12-month follow-up evaluations. ${ }^{*} p<.05$

\section{Secondary Outcomes}

Self-Concept (AF-5). The ANCOVA revealed a statistically significant difference in the dimension of family self-concept at the 8-month follow-up, controlling for baseline family self-concept, $F(73)=9.67, p=.003, n=75, d=0.56$, such that youth in the intervention group had significantly better family self-concepts at the 8-month evaluation than did youth in the control group. The magnitude of the effect size was medium. No statistically significant differences were found on the other self-concept dimensions or the total score (see Table 4).

Warvick-Edinburgh Mental Well-being Scale (WEMWBS). Youth in the intervention group reported significantly greater psychological well-being than those in the control group at the four-month evaluation (see Table 4), even when controlling for level of depressive symptoms at baseline. The magnitude of the effect size was medium. No statistically significant group differences were found on the WEMWBS at the 8-month (effect size: $d=0.22$ ) or 12-month evaluations (effect size: $d=-0.01)$.

Table 4. Descriptives (means and standard deviations) and ANCOVAS for measures of self-concept (AF-5) and well-being (WEMWBS)

\begin{tabular}{llllllllll}
\hline Variable & Control & \multicolumn{2}{l}{ Group } & Smile & Program & $\boldsymbol{F}(\mathbf{d f})$ & $\boldsymbol{p}$ & Effect size \\
\hline AF-5 Self-concept Scale & Mean & $n$ & $S D$ & Mean & $n$ & $S D$ & & & \\
\hline \multicolumn{1}{l}{ Pre-intervention } & 31.4 & 33 & 6.6 & 30.3 & 47 & 6.7 & -- & & \\
$\quad$ Post-intervention & 33.0 & 33 & 6.9 & 32.4 & 47 & 6.0 & $0.2(1.78)$ & .66 & .01 \\
at 8months & 32.1 & 29 & 6.8 & 33.0 & 47 & 6.3 & $0.8(1.74)$ & .36 & .27 \\
at 12months & 33.7 & 29 & 6.7 & 32.1 & 47 & 6.3 & $1.6(1.74)$ & .21 & -.14 \\
\hline Well-being (WEMWBS) & & & & & & & & & \\
\hline at 4months & 50.1 & 27 & 9.6 & 55.2 & 33 & 9.6 & $t=-2.1(58)$ & $\mathbf{. 0 4 3}$ &. $\mathbf{5 3}$ \\
at 8months & 52.0 & 34 & 9.3 & 53.4 & 47 & 9.3 & $t=-1.0(79)$ & .33 & .22 \\
at 12months & 50.6 & 31 & 9.3 & 50.5 & 47 & 9.3 & $t=0.5(76)$ & .96 & -.01 \\
\hline
\end{tabular}

Notes: The results of the total scores of the measures are presented. AF-5 = Self-Concept Scale Form 5; WEMWBS $=$ Warwick-Edinburgh Mental Wellbeing Scale 


\section{Discussion and Conclusions}

The main objective of this randomized controlled trialwas to evaluate the effectiveness of the Smile Program in decreasing or preventing increases in depressive symptoms and promoting well-being in youth. Assessments were conducted at preand post-intervention and at 8- and 12-month follow-ups.

\section{Primary Outcome: Reduction of Depressive Symp- toms}

Overall, the Smile Program had a significant short-term effect on children's depressive symptoms. Youth in the intervention condition reported significantly lower levels of depressive symptoms at the post-intervention assessment as compared to youth in the control condition, controlling for baseline CDI scores. These short-term positive results are consistent with other studies of depression prevention programs with universal samples (e.g., Horowitz et al., 2007, Merry et al., 2004; Spence, Sheffield, \& Donovan, 2003, 2005). In general, the average effect size of universal interventions have been found to be low (Horowitz \& Garber, 2006; Stice et al., 2009), with only $22 \%$ of universal prevention studies reporting statistically significant effects (Chaplin et al., 2006; Horowitz et al., 2007; Merry et al., 2004). As a consequence, some authors have questioned the utility of conducting preventive interventions with universal samples (Spence \& Shortt, 2007). In the current study, the Smile Program produced a medium-low effect size with respect to depressive symptoms at post-intervention, which thus provides further evidence of the short-term efficacy of a depression prevention program in a universal sample.

A similar, although nonsignificant, pattern of results was found for parents' reports of their children's depressive symptoms. Youth in the intervention group tended to have lower parent-reported depressive symptoms at postintervention than youth in the control group. The lack of significance may have been due to low statistical power given the small number of parent reports $(n=56)$. A statistically significant difference was found, however, on parents' report on the CDI negative self-esteem subscale, indicating that at the post-intervention evaluation, youth in the intervention group had significantly better self-esteem as compared to those in the control group.

With regard to longer-term effects, no statistically significant differences were found at either the 8- or 12-month assessments of depressive symptoms. Failure to maintain the short-term benefits of preventive interventions has been found in several studies with universal samples (Horowitz et al., 2007; Merry et al., 2004; Spence, Sheffield, \& Donovan, 2003, 2005). Thus, although the Smile Program had short-term effects on lowering depressive symptoms, it might not have been powerful enough to sustain these benefits. Therefore, some kind of continuation or booster sessions might be needed to maintain and extend the earlier positive effects (e.g., Beardslee et al., 2013).

\section{Secondary Outcomes}

Although self-concept typically has not been assessed as an outcome in studies of the prevention of depression, given its strong association with depression, we examined the program's effect on this variable. No significant difference was found on overall self-concept at post-intervention, controlling for pre-intervention scores; at the 8-month follow-up, however, youth in the intervention group reported significantly better family self-concept than did youth in the control group. The magnitude of the effect size was medium. At 4 months post-intervention, youth in the Smile Program reported significantly greater psychological well-being on the Warwick-Edinburgh Mental Well-being Scale as compared to those in the control group, even when youths' level of baseline depressive symptoms was controlled. The magnitude of the effect size was medium. Thus, the measure of well-being seemed to assess something over and above depression. No statistically significant group differences on psychological well-being were found at the 8- or 12-month follow-ups, although the average level of psychological well-being in the intervention group remained higher than in the control group. Methodological strengths of the study included the comparison of an experimental intervention group with a control group, random assignment of participants across multiple centers, evaluation of positive variables, and follow-up assessments at 8 and 12 months. Limitations of the study provide directions for future research. First, the comparison group did not control for nonspecific factors. Future randomized controlled trials should contrast the Smile Program with a nonspecific control group in addition to a no intervention group (e.g., Pössel, Martin, Garber \& Hautzinger, 2013; Stice et al., 2010). Nevertheless, the current study was an important first step in testing whether the Smile Program worked at all over and above assessment only. Second, the relatively low participation rate limits the extent to which the findings can be generalized to the broader population. Also, the sample size was small, which reduced power to detect significant effects. Several nonsignificant trends were noted that should be interpreted with caution, but nevertheless highlight variables to be evaluated in the future with larger samples.

Third, although the study aimed to test the program using an indicated sample, the low participation rate necessitated offering the intervention more universally. Given that depression prevention programs provided to universal samples have not done as well as targeted samples (Horowitz \& Garber; 2006, Stice et al., 2009), future tests of the Smile Program should be conducted with selective or indicated samples.

Finally, future studies of the Smile Program should measure the skills taught in the intervention (Horowitz et al., 2007; Pattison \& Lynd-Stevenson, 2001), conduct appropriate assessments of fidelity and competence of those providing the program (Gillham, Brunwasser, \& Freres, 2008), implement booster sessions and longer follow-up assessments (Compas et al., 2004; Garber et al., 2009; Gladstone, 2009; Shore, 
Toumbourou, Lewis \& Kremer, 2017; Stice et al., 2009), test new technologies such as the internet for implementing prevention programs (Calear \& Christensen, 2010), and evaluate the cost-effectiveness of the intervention. In summary, there is a clear need to invest in interventions to prevent depression in young people in general, and particularly in Spain (Sanchez-Hernandez et al., 2014), given the increasing evi-

\section{References}

Arnarson, E. O., \& Craighead, W. E. (2011). Prevention of depression among Icelandicadolescents: A 12-month follow-up. Behaviour Research and Therapy, 49, 170- 174.

Ato, M., \& Vallejo, G. (2011). Los efectos de terceras variables en la investigación psicológica. Anales de Psicología, 27, 550-561.

Beardslee, W.R., Brent, D.A., Weersing, V.R., Clarke, G.N., Porta, G., Hollon, S.D., Gladstone, T.R.G., Gallop, R., Lynch, F.L., Iyengar, S., DeBar, L., \& Garber, J. (2013). Prevention of depression in at-risk adolescents: Longer-term effects. Journal of the American Medical Association Psychiatry, 70(11), 1161-1170.

Beddington, J., Cooper, C. L., Field, J., Goswami, U., Huppert, F. A., Jenkins, R., Jones, H. S., Kirkwood, T. B. L., Sahakian, B. J., \& Thomas, S. M. (2008). The mental wealth of nations. Nature, 455, 1057-1060.

Bustamante V. F., \& Florenzano U. R. (2013). Programas de prevención del suicidio adolescente en establecimientos escolares: una revisión de la literatura. Revista chilena de neuro-psiquiatría, 51(2), 126-136.

Calear, A. L. \& Christensen, H. (2010). Review of internet-based prevention and treatment programs for anxiety and depression in children and adolescents. The Medical Journal of Australia, 192(11), S12-S14

Calvete, E. \& Cardeñoso, O. (2001). Creencias, Resolución de Problemas Sociales y Correlatos Psicológicos. Psicothema, 13(1), 95-100.

Chaplin, T. M., Gillham, J. E., Reivich, K., Elkon, A. G., Samuels, B., Freres, D. R., et al., (2006). Depression prevention for early adolescent girls: A pilot study of all girls versus co-ed groups. Journal of Early Adolescence, 26, 110-126.

Chartier, M., Stoep, A. V., McCauley, E., Herting, J. R., Tracy, M. \& Limp, J. (2008). Passive versus Active Parental Permission: Implications for the Ability of School-Based Depression Screening to Reach Youth at Risk. Journal of School Health, 78(3), 157-164.

Cohen, J. (1988). Statistical power analysis for the behavioral sciences $\left(2{ }^{a}\right.$ ed). Hillsdale, Nueva Jersey: Erlbaum.

Compas, B. E. \& Forehand, R. (2004). Family cognitive-behavior prevention of depression. National Institute of Mental Health (R01MH069940).

Cooke, A., Friedli, L., Coggins, T., Edmonds, N., Michaelson, J., O’Hara, K., Snowden, L., Stansfield, J., Steuer, N., Scott-Samuel, A. (2011) Mental Well-being Impact Assessment 3rd ed. London: National MWIA Collaborative.

Cooper, H. (2010). Research synthesis and meta-analysis: A step-by-step approach ( $3^{\text {rd ed. }) . ~ T h o u s a n d ~ O a k s, ~ C A: ~ S a g e . ~}$

Cuijpers, P. (2003). Examining the effects of prevention programs on the incidence of new cases of mental disorders: The lack of statistical power. American Journal of Psychiatry, 160, 1385-1391.

Del Barrio, V. \& Carrasco, M.A. (2004). CDI. Inventario de depresión infantil. Madrid: TEA.

Del Barrio, V., Roa, M.L., Olmedo, M. \& Colondrón, F. (2002). Primera adaptación del CDI-S a población española. Acción Psicológica, 3, 263272.

Ferreira, E., Granero, R., Noorian, Z., Acosta, K. R., \& DomènechLlaberia, E. (2012). Acontecimientos vitales y sintomatología depresiva en población adolescente. Revista de psicopatología y psicología clínica, 17(2), 123-135.

Figueras, A., Amador, J. A., Gómez, J., \& Del Barrio, V. (2010). Psychometric Properties of the Children's Depression Inventory in Community and Clinical Sample. The Spanish Journal of Psychology, 13(2), 990-999. dence of positive effects on personal and social development as a result of such interventions (Merry et al., 2011).

Acknowledgements.- The authors wish to thank the collaboration of San Buenaventura PP Capuchinos School, Maristas School, Jesús María School, Infante Don Juan Manuel School, Miguel de Cervantes School, Miguel Espinosa School and Abanilla School of Murcia. The study was funded with a grant-PhD at the University of Murcia.

Frias, M. D., Pascual, J. \& García, J. F. (2000). Tamaño del efecto del tratamiento y significación estadística. Psicothema, 12(2), 236-240

Garber, J. (2006). Depression in children and adolescents. Linking risk research and prevention. American Journal of Preventive Medicine, 31(61), 104-125.

Garber, J., Clarke, G., Weersing, V. R., Beardslee, W.R., Brent, D.A., Gladstone, T.R.G., Debar, L., Lynch, F., D'Angelo, E., Hollon, S.D., Shamseddeen, W., \& Iyengar, S. (2009). Prevention of depression in atrisk adolescents: A randomized controlled trial. Journal of the American Medical Association. 301(21), 2215-2224. [doi:10.1001/jama.2009.788] PMCID: PMC2737625

García, F. \& Musitu, G. (2001) Autoconcepto Forma 5 (AF5). Madrid, España: TEA.

Gardner, H. (2005). Inteligencias múltiples: La teoría en la práctica. Barcelona. Editorial Paidos Ibérica.

Gladstone, T.R.G., \& Beardslee, W.R. (2009). The Prevention of Depression in Children and Adolescents: A Review. Canadian Journal of Psychiatry, 54(4), 212-221.

Gillham, J.E., Brunwasser, S.M., \& Freres, D.R. (2008). Preventing depression early in adolescence: The Penn Resiliency Program. In J.R.Z. Abela \& B.L. Hankin (Eds.) Handbook of depression in children and adolescents (pp. 309-332). New York: Guilford Press.

Gillham, J. E., Hamilton, J., Freres, D. R., Patton, K. \& Gallop, R. (2006). Preventing depression among early adolescents in the primary care setting: A randomized controlled study of the Penn Resiliency Program. Journal of Abnormal Child Psychology, 34, 203-219.

Gillham, J. E., Reivich, K. J., Freres, D. R., Chaplin, T. M., Shatte, A. J., Samuels, B., et al. (2007). School-based prevention of depressive symptoms: A randomized controlled study of the effectiveness and specificity of the Penn Resiliency Program. Journal of Consulting and Clinical Psychology, 75, 9-19.

Gillham, J.E., Reivich, K.J., Jaycox, L.H., \& Seligman, M.E.P. (1995). Prevention of depressive symptoms in schoolchildren: Two-year followup. Psychological Science, 6, 343-351.

Hankin, B. L., Abramson, L. Y., Moffitt, T. E., Silva, P. A., McGee, R. \& Angell, K. E. (1998). Development of depression from preadolescence to young adulthood: Emerging gender differences in a 10-year longitudinal study. Journal of Abnormal Psychology, 107(1), 128-140.

Hayes, A.F. (2013). Introduction to mediation, moderation, and conditional process analysis: a regression-based approach. New York, NY: Guilford Press.

Helliwell, J., Layard, R., \& Sachs, J (2013). World Happiness Report 2013. New York: UN Sustainable Development solutions network. Disponible en: http://unsdsn.org/files/2013/09/WorldHappinessReport2013_online. pdf

Hollingshead, A. B. (2011). Four factor index of social status. Yale Journal of Sociology, 8, 21-51.

Horowitz, J. L. \& Garber, J. (2006). The prevention of depressive symptoms in children and adolescents: A meta-analytic review. Journal of Consulting and Clinical Psychology, 74, 401-415.

Horowitz, J.L., Garber, J., Ciesla, J.A., Young, J., \& Mufson, L. (2007). Prevention of depressive symptoms in adolescents: A randomized trial of cognitive-behavioral and interpersonal prevention programs. Journal of Consulting and Clinical Psychology, 75, 693-706.

Huppert, F.A. (2009). A new approach to reducing disorder and improving well-being. Perspectives on Psychological Science, 4(1), 108-111 
King, M. B., Nazareth, I., Levy, G., Walker, C., Morris, R., Weich, S., Bellón-Saameño, J., Moreno, B., Svab, I., Rotar, D., Rifel, J., Maaroos, H., Aluoja, A., Kalda, R., Neeleman, J., Geerlings, M., De Almeida, X. M, Correa, B., \& Torres-Gonzalez, F. (2008). Prevalence of common mental disorders in general practice attendees across Europe: The PREDICT study. British Journal of Psychiatry, 192, 362-367.

Kovacs, M. (1992). Manual of the Children's Depression Inventory. Toronto: Multi- Heath Systems, Inc

Meltzer, H., Gatward, R., Goodman, R., \& Ford, T. (2000). The mental bealth of children and adolescents in Great Britain. London: The Stationary Office.

Méndez, J., Olivares, J., \& Ros, C. M. (2001). Características clínicas y tratamiento de la depresión en la infancia y adolescencia. En V. E. Caballo, \& M. A. Simón (Eds.). Manual de Psicología Clinica Infantily del Adolescente (pp. 139-185). Madrid. Pirámide.

Merry, S., McDowell, H., Wild, C., Bir, J. y Cunliffe, R. (2004). A randomized placebo-controlled trial of a school based depression prevention program. Journal of the American Academy of Child and Adolescent Psychiatry, 43, 538- 547.

Merry, S. N., Hetrick, S.E., Cox, G.R., Brudevold-Iversen, T., Bir, J.J., McDowell, H. (2011). Psychological and educational interventions for preventing depression in children and adolescents. Cochrane Database of Systematic Reviews, Issue 12. Art. No.: CD003380. DOI: 10.1002/14651858. CD003380.pub3.

Mihalopoulos, C., Vos, T., Pirkis, J., Smit, F., \& Carter, R. (2011). Do indicated preventive interventions for depression represent good value for money? Australian and New Zealand Journal of Psychiatry, 45(1), 36-44. doi:10.3109/00048674.2010.501024

Morris, S.B. (2000). Distribution of the standardized mean change effect size for metaanalysis on repeated measures. British Journal of Mathematical \& Statistical Psychology, 53, 17-29.

Morris, S.B. y DeShon, R.P. (2002). Combining effect size estimates in meta-analysis with repeated measures and independent-groups designs. Psychological Methods, 7, 105-125.

Pattison, C. \& Lynd-Stevenson, R.M. (2001). The prevention of depressive symptoms in children: The immediate and long-term outcomes of a school based program. Behaviour Change, 18, 92-102.

Pössel, P., Horn, A. B., Groen, G. \& Hautzinger, M. (2004). School-based Universal Primary Prevention of Depressive Symptoms in Adolescents: Results of a 6-Month Follow-up. Journal of the American Academy of Child and Adolescent Psychiatry, 43, 1003-1010.

Pössel, P., Martin, N. C., Garber, J., \& Hautzinger, M. (2013). A randomized controlled trial of a cognitive-behavioral program for the prevention of depression in adolescents compared with nonspecific and nointervention control conditions. Journal of Counseling Psychology, 60(3), 432-438. doi:10.1037/a0032308

Roberts, C., Kane, R., Thomson, H., Bishop, B. \& Hart, B. (2003). The prevention of depressive symptoms in rural school children: A randomized controlled trial. Journal of Consulting and Clinical Psychology, 71, 622-628

Sánchez-Hernández, Ó. \& Méndez, F. X. (2009). Programa Sonrisa. Manuscrito no publicado.
Sánchez-Hernández, O., Méndez, F. X., \& Garber, J. (2014). Prevención de la depresión en niños y adolescentes: Revisión y reflexión. Revista de Psicopatología y Psicología Clínica, 19(1),63-76.

Sánchez Meca, J., \& Botella, J. (2010). Revisiones sistemáticas y metaanálisis: Herramientas para la práctica profesional. Papeles del Psicólogo, 31(1), 7-17

Seligman, M. E. P. \& Csikszentmihalyi, M. (2000). Positive psychology: An introduction. American Psychologist, 55, 5-14.

Seligman, M. E., Schulman, P. \& Tryon, A. M. (2007). Group prevention of depression and anxiety symptoms. Behavior Research and Therapy, 45, 1111-1126.

Shore, L., Toumbourou, J. W., Lewis, A. J., \& Kremer, P. (2017). Review: Longitudinal trajectories of child and adolescent depressive symptoms and their predictors - a systematic review and meta-analysis. Child and Adolescent Mental Health, doi:10.1111/camh.12220

Southwick, S. M., Vythilingam, M., \& Charney, D. S. (2005). The psychobiology of depression and resilience to stress: Implications for prevention and treatment. Annual Review of Clinical Psychology, 1, 255-291.

Spence, S. H., Sheffield, J. K. y Donovan, C. L. (2003). Preventing adolescent depression: An evaluation of the Problem Solving for Life program. Journal of Consulting and Clinical Psychology, 71, 3-13.

Spence, S. H., Sheffield, J. K. y Donovan, C. L. (2005). Long-term outcome of a school- based, universal approach to prevention of depression in adolescents. Journal of Consulting and Clinical Psychology, 73,160-167.

Spence, S. H. y Shortt, A. L. (2007). Research Review: Can we justify the widespread dissemination of universal, schoolbased interventions for the prevention of depression among children and adolescents? Journal of Child Psychology and Psychiatry, 48(6), 526-542

Stice, E., Rohde, P., Seeley, J. y Gau, J. (2010). Testing Mediators of Inter vention Effects in Randomized Controlled Trials: An Evaluation of Three Depression Prevention Programs. Journal of Consulting and Clinical Psychology, 78(2), 273-280.

Stice, E., Shaw, H., Bohon, C., Marti, C.N., \& Rohde, P. (2009). A metaanalytic review of depression prevention programs for children and adolescents: Factors that predict magnitude of intervention effects. Journal of Consulting and Clinical Psychology, 77(3), 486-503.

Sutton, J. M. (2007) Prevention of depression in youth: A qualitative review and future suggestions. Clinical Psychology Review, 27, 552-571.

Tennant, R., Hiller, L., Fishwick, R., Platt, S., Joseph, S., Weich, S., Parkinson, J., Secker, J., \& Stewart-Brown, S. (2007). The WarwickEdinburgh Mental Well-being Scale (WEMWBS): Development and UK validation. Health and Quality of Life Outcomes, 63(5), 1477-7525.

Tomas, J.M. \& Oliver, A. (2004). Análisis psicométrico confirmatorio de una medida multidimensional del autoconcepto en español. Interameri can Jounal of Psychology, 38(2), 285-293.

Valera-Espín, A., Sánchez Meca, J., \& Marín Martínez, F. (2000). Contraste de hipótesise investigación psicológica española: Análisis y propuestas. Psicothema, 12(12), 549-552.

Vázquez, C., Nieto, M., Hernangómez, L., \& Hervás, G. (2005). Tratamiento psicológico en un caso de depresión mayor. En J. P. Espada, J. Olivares, J. y F. X. Méndez (dirs.), Terapia psicológica: casos prácticos (pp. 201-231). Madrid: Pirámide. 